Revista Aportes para la Integración Latinoamericana Año XXIV, N ${ }^{\circ} 39 /$ Diciembre 2018, ISSN 2468-9912. DNDA: 5355295 en línea

Noemí Mellado

"MERCOSUR: de lo regional a lo subnacional"

\title{
MERCOSUR: DE LO REGIONAL A LO SUBNACIONAL
}

La Integración Latinoamericana se desarrolla transitando comportamientos multinivel. La incidencia de lo subnacional en lo regional y viceversa configura una dinámica de retroalimentación cuyo abordaje resulta de relevancia atento a las implicaciones mutuas que se producen. En el presente número se hace llegar al lector tres profundas reflexiones sobre esta problemática.

En razón de las realidades involucradas, se publica en la Sección Tema Central el trabajo de la Dra. Isabel Clemente Batalla, de la Universidad de la República del Uruguay titulado: Integración regional y desarrollo: experiencias de desarrollo local en el MERCOSUR en el que se analiza la asociación de "integración regional" y "desarrollo" como fundamento para la organización de los bloques de integración en América Latina. La autora propone una mirada sobre el desarrollo local como modelo que incluye la dimensión territorial y los objetivos de desarrollo social, en un proceso favorecido por los avances hacia la descentralización, el empoderamiento de las comunidades locales y la creación de nuevos vínculos entre diferentes escalas espaciales: global, regional, nacional y local sub-nacional. El artículo examina los alcances de las experiencias del modelo de desarrollo local en el proceso de integración de MERCOSUR, en sus dimensiones territorial, económico-social y cultural y el papel cumplido por la iniciativa local.

En la sección Estudios se ha incluido el trabajo del Mg. Gabriel Comparato (De) construyendo la integración regional. Una reflexión multidimensional a partir del turismo y el patrimonio. El texto evidencia una reflexión crítica a partir de un doble alcance. En primera instancia, persigue interpelar las formas tradicionales de abordar la integración a partir de la incorporación de la tesis de lo "multi" incluyendo una complejidad: multiescalar, multiformal, multidimensional, multinivel, multiactoral y multicausal. Por otro lado, busca analizar las potencialidades integrativas en las que puede devenir un proceso de integración a partir del uso turístico del patrimonio. Se reivindica, por tanto, al uso turístico del patrimonio como una estrategia política que trasciende la óptica comercialista y, en su defecto, imbrica diferentes dimensiones y distintos actores en dicho proceso. Metodológicamente, se parte de un análisis y triangulación bibliográfica interdisciplinar y, a los efectos de considerar correlato empírico, se consideraran los resultados alcanzados en la tesis de maestría en 2016: "El uso turístico del patrimonio jesuítico-guaraní en Mercosur. Una oportunidad de Integración regional" (IIL - UNLP).

El trabajo La política internacional subnacional: desafíos para los municipios de la provincia de Buenos Aires en el siglo XXI de los Dres. Sebastián Piana, Juan Cruz Tisera y la Mag. María Soledad Manassero se ha incorporado en la sección Opinión. En él se presenta la Política Internacional Subnacional como un fenómeno relativamente novedoso en el contexto de la provincia de Buenos Aires. Los autores buscan identificar características del proceso de influencia de doble vinculación entre la sociedad internacional y los gobiernos subnacionales (municipales), describiendo un fenómeno que ha sido identificado como glocal. Desde el campo de las Relaciones Internacionales, proponen establecer un marco teórico que analiza el despertar internacional de los actores subnacionales. En un contexto denominado Sociedad Internacional Global, se determinan las modificaciones del carácter central y unitario del Estado-Nación propuesto por el realismo político. 